\title{
O uso do duolingo no ensino de língua inglesa em curso técnico de nível médio integrado
}

\author{
Kássio Roberto Brito Soares ${ }^{1}$ \\ Samuel de Carvalho Lima ${ }^{2}$
}

\begin{abstract}
Resumo
Neste trabalho, apresentamos uma narrativa de ensino com o uso do aplicativo Duolingo em aulas de língua inglesa em uma turma de $4^{\circ}$ ano do Curso Técnico de Nível Médio Integrado em Meio Ambiente no Instituto Federal de Educação, Ciência e Tecnologia do Rio Grande do Norte, campus Ipanguaçu. Fundamentados nas concepções do m-learning, nossa intervenção pedagógica foi realizada em 7 encontros presenciais no ano de 2017, totalizando 12h/a. Nossa experiência contou com a participação de 31 alunos com idades entre 17 e 19 anos e integrou o uso de smartphones e os componentes curriculares previstos no Projeto Pedagógico de Curso (PPC). O êxito da nossa experiência se reflete no interesse imediato dos alunos pela possibilidade de aprender inglês utilizando um aplicativo que se assemelha a um jogo,o que pode ser corroborado pelas anotações no diário reflexivo feitas pelo professor. Concluímos que o Duolingo pode se configurar uma ferramenta de suporte ao ensino de gramática e vocabulário em língua inglesa, quando em seu uso estiver previsto o planejamento que considere os interesses dos alunos e os objetivos da disciplina.
\end{abstract}

Palavras-Chave: Ensino. Inglês. Duolingo.

\begin{abstract}
In this paper, we present a teaching narrative with the use of Duolingo application in English classes in a4th year group of Environment Program Integrated into High School at Federal Institute of Education, Science and Technology of Rio Grande do Norte, campus Ipanguaçu. Based on the conceptions of m-learning, our pedagogical intervention was carried out in 7 face-to-face meetings in 2017, resulting in 12 classes. Our experience counted on the participation of 31 students between the ages of 17 and 19 and integrated the use of smartphones and the syllabus foreseen in the Pedagogical Course Project (PPC). The success of our experience is reflected in the students' immediate interest in being able to learn English using a game-like application, which can be corroborated by the teacher's reflective journal entries. We conclude that Duolingo can be a tool to support the teaching of English grammar and vocabulary, when in its use there is planning that considers the students' interests and the course objectives.
\end{abstract}

Keywords: Teaching. English. Duolingo.

\section{Introdução}

É notável o espaço que as tecnologias vêm ganhando no cotidiano das pessoas. Através do uso de notebooks, smartphones e tablets, a tecnologia está se incorporando nas

\footnotetext{
${ }_{1}^{1}$ Mestre em Ensino pelo Programa de Pós-Graduação em Ensino (POSENSINO). Professor de língua inglesa do Instituto Federal do Rio Grande do Norte, campus Ipanguaçu. E-mail: kassio.soares@ifrn.edu.br

2 Pós-doutor em Ciências da Educação pela Universidade do Minho. Professor de língua inglesa do Instituto Federal do Rio Grande do Norte, campus Mossoró. E-mail: samuel.lima@ifrn.edu.br
}

LínguaTec, Instituto Federal de Educação, Ciência e Tecnologia do Rio Grande do Sul, Bento Gonçalves v. 3, n. 1, p. 158-170, jun. 2019. 
mais variadas tarefas de seus usuários, muitas vezes, através de aplicativos com inúmeras funcionalidades.

No contexto de ensino-aprendizagem, a tecnologia demonstrou que a interatividade permite o maior e o mais rápido acesso à informação. Datashow, tablets, lousas digitais, jogos, redes sociais, vídeos e sites educativos se tornaram parceiros de professores e alunos. Com a popularização dos smartphones, professores e alunos têm tido acesso a aplicativos que, por exemplo, promovem o ensino-aprendizagem de línguas estrangeiras, como é o caso do Duolingo.

Para Moura (2010), o mobile learning (m-learning) é produtivo. Sua compreensão possibilita que os alunos incorporem seus smartphones com naturalidade às suas atividades de estudo, fazendo uso das funcionalidades da tecnologia móvel em diferentes atividades curriculares, realizadas dentro ou fora da sala de aula, em grupos ou de forma individual.

Diante dessas reflexões e na senda das propostas de ensino de línguas no contexto da Educação Profissional e Tecnológica (GUERRA, 2017; SILVA, 2018; PINTO; LIMA, 2018; REIS; LIMA, 2018), desenvolvemos uma proposta de ensino com o uso do aplicativo Duolingo em aulas de língua inglesa em uma turma do $4^{\circ}$ ano do Curso Técnico de Nível Médio Integrado em Meio Ambiente no Instituto Federal de Educação, Ciência e Tecnologia do Rio Grande do Norte (IFRN), campus Ipanguaçu. Nossa intervenção pedagógica foi realizada em 7 encontros presenciais no ano de 2017, totalizando 12h/a (cf. SOARES, 2018). Nossa experiência contou com a participação de 31 alunos com idades entre 17 e 19 anos e integrou o uso de smartphones e os componentes curriculares previstos no Projeto Pedagógico de Curso (PPC).

A nossa narrativa de ensino está dividida em 5 partes. Além destas considerações iniciais, a seguir, apresentamos os pressupostos teóricos com o intuito de conceituar o $\mathrm{m}$ learning. Posteriormente, descrevemos as características do contexto educativo em que propusemos o ensino de inglês através do uso do Duolingo. Na seção da narrativa de ensino, apresentamos a síntese das aulas com anotações realizadas no diário reflexivo do professor. Por fim, em nossas considerações finais, refletimos sobre as implicações pedagógicas da nossa experiência. 


\section{Pressupostos teóricos}

A escola tem se valido das tecnologias digitais para a mediação pedagógica de conteúdos específicos das disciplinas curriculares. No entanto, vale lembrar o que afirma Kenski (2007, p.124): “os recursos tecnológicos, por si sós, não garantem melhora no aprendizado e na qualidade da educação [...]". Ou seja, dentro das escolas ainda precisamos pensar sobre políticas e práticas educacionais que possibilitem que professores e alunos compreendam os usos das tecnologias em função de uma educação inclusiva, emancipatória e significativa.

Diante do contexto de uso de diferentes tecnologias na educação, Geddes (2004) conceitua o m-learning como a aquisição de conhecimento e habilidade através da utilização da tecnologia móvel, não importando a hora ou o lugar. Com recursos cada vez mais avançados presentes nos dispositivos móveis, abre-se uma variedade de oportunidades para que as escolas passem a aplicar essas tecnologias ao processo de ensino-aprendizagem, tanto para o público em sala de aula, ambiente presencial, quanto fora delas, através da semipresencialidade ou da Educação a Distância.

Para Sharma et al. (2006), o m-learning é mais um processo de aprendizagem que destaca as vantagens que os dispositivos móveis têm em relação às interfaces inteligentes. Ainda de acordo com os autores, ao se adotar a aprendizagem através do m-learning estamos propiciando não só um avanço pedagógico mas também contribuindo nas aulas práticas e seus conteúdos curriculares.Hoje em dia, o foco deixou de ser predominantemente tecnológico, portanto faz-se necessário refletir sobre as implicações sociais dessas práticas educacionais.

Saccol, Schlemmer e Barbosa (2011) destacam a natureza autodidata do m-learning assim como o caráter informal de sua apresentação.É com base nesses pressupostos que integramos o aplicativo Duolingo nas aulas de inglês como língua estrangeira de modo a despertar o interesse dos alunos pela aprendizagem de alguns dos conteúdos prescritos no Projeto Pedagógico de Curso (PPC), a saber: estruturas gramáticas, vocabulário básico, entre 
outros. Diante dessa perspectiva, salientamos ainda que o Duolingo

[...] tem ganhado bastante espaço no contexto de ensino e aprendizagem de línguas desde seu lançamento em 2012. No Duolingo, são oferecidas atividades de escrita na língua escolhida, e os usuários progridem nas habilidades à medida que têm êxito nas lições. O Duolingo pode ser acessado em sua versão em site ou em aplicativo, disponível para download nos sistemas Android e iOS. (DUARTE; ALDA; LEFFA, 2016, p. 120).

A seguir, apresentamos o contexto educativo da nossa experiência, de modo a descrever as condições favoráveis para que uma proposta de ensino com o Duolingo possa ser realizada.

\section{Contexto educativo}

Nossa experiência foi realizada no horário regular das aulas da disciplina Inglês II em uma turma do 4을 ano do Curso Técnico de Nível Médio Integrado em Meio Ambiente do IFRN, campus Ipanguaçu. A disciplina Inglês II possui uma carga horária anual de 90h, distribuídas em 3 h/a semanais. No IFRN, a hora/aula é de $45 \mathrm{~min}$.

Nossos alunos são oriundos dos municípios da região do Vale do Açu e outras localizações como as cidades de Afonso Bezerra, Paraú, Pedro Avelino e Triunfo Potiguar. Esse público passa pelo exame de seleção, que é o processo seletivo para ingresso nos cursos técnicos integrados do IFRN que segue uma política de cotas sociais e raciais nas instituições federais de ensino, reservando $50 \%$ das vagas existentes para alunos egressos das escolas públicas, de acordo com a lei no 12.711/2012.

Vale destacar que, quanto às instalações físicas do IFRN, estas podem ser consideradas boas, levando-se em consideração as condições estruturais das instituições públicas inseridas na Região do Vale do Açu. As aulas foram ministradas em sala climatizada, com bom espaço físico, lousa para pincel atômico, projetor portátil e com acesso à internet, ferramenta primordial para essa intervenção já que é realizada a partir de uma tecnologia móvel. Sobre a intervenção pedagógica, ressaltamos que são 
[...] as interferências (mudanças, inovações), propositadamente realizadas, por professores/pesquisadores, em suas práticas pedagógicas. Tais interferências são planejadas e implementadas com base em um determinado referencial teórico e objetivam promover avanços, melhorias, nessas práticas, além de pôr à prova tal referencial, contribuindo para o avanço do conhecimento sobre os processos de ensino/aprendizagem neles envolvidos. (DAMIANI, 2012, p. 2884).

É importante ressaltar também que, quanto ao comportamento dos alunos, não há registros de indisciplina em sala de aula, e as aulas transcorreram de forma tranquila. Sabemos, porém, que aprender uma língua estrangeira é uma tarefa complexa, exigindo, portanto, uma postura ativa e participativa, tanto do professor, quanto do aluno. Sabemos também que o aplicativo Duolingo possui potencialidades e limitações, sobretudo em relação ao feedback, e que seu uso deve ser complementado pelas interações entre professor e alunos na sala de aula regular.

[...] o Duolingo traz um feedback corretivo explícito, indicando o erro e mostrando as formas corretas, quando há mais de uma possibilidade. O sistema não apresenta feedback metalinguístico, mas oferece um espaço para que os jogadores solicitem ajuda e possam receber esse tipo de explicação e uma explicação prévia, antes de iniciar algumas atividades, sobre o tópico linguístico ou gramatical a ser abordado. (DUARTE; ALDA; LEFFA, 2016, p. 125).

A seguir, apresentamos nossa narrativa de ensino através da síntese das aulas. Nossa experiência foi realizada. Os dados foram divididos em função dos encontros: 7 encontros semanais. As informações foram organizadas da seguinte forma: apresentação dos objetivos do encontro; descrição dos procedimentos durante a aula; anotação emergente das notas do diário reflexivo do professor.

\section{Narrativa de ensino: síntese das aulas}

Nosso primeiro encontro teve a duração de $2 \mathrm{~h} / \mathrm{a}$.Os objetivos do primeiro encontro foram os seguintes:instalar o aplicativo Duolingo nos smartphones dos alunos e explicar seus usos nas aulas; iniciar o assunto gramatical Personal Pronouns; apresentar alguns verbos e vocabulários.Em relação aos procedimentos da aula, após uma breve apresentação dos 
alunos, deu-se início à instalação do aplicativo Duolingo e o cadastramento nos seus smartphones. Em seguida, deu-se início à primeira atividade desenvolvida, a explicação do conteúdo Personal Pronouns. A segunda atividade foi desenvolvida no aplicativo Duolingo, através da realização das primeiras lições já disponíveis no aplicativo. Esse tipo de atividade leva o aluno a pensar não somente no vocabulário envolvido, mas também na estrutural gramatical que melhor se adequa a frase. É importante frisar que o próprio aplicativo mostra para o aluno se a frase foi respondida de forma correta, fazendo a referência ao modelo de um jogo e traz também a tradução da frase respondida. A seguir, na Fig. 1, podemos observar uma das atividades de gramática do Duolingo solicitando a identificação de qual pronome pessoal em inglês se adequa melhor na estrutura da frase.

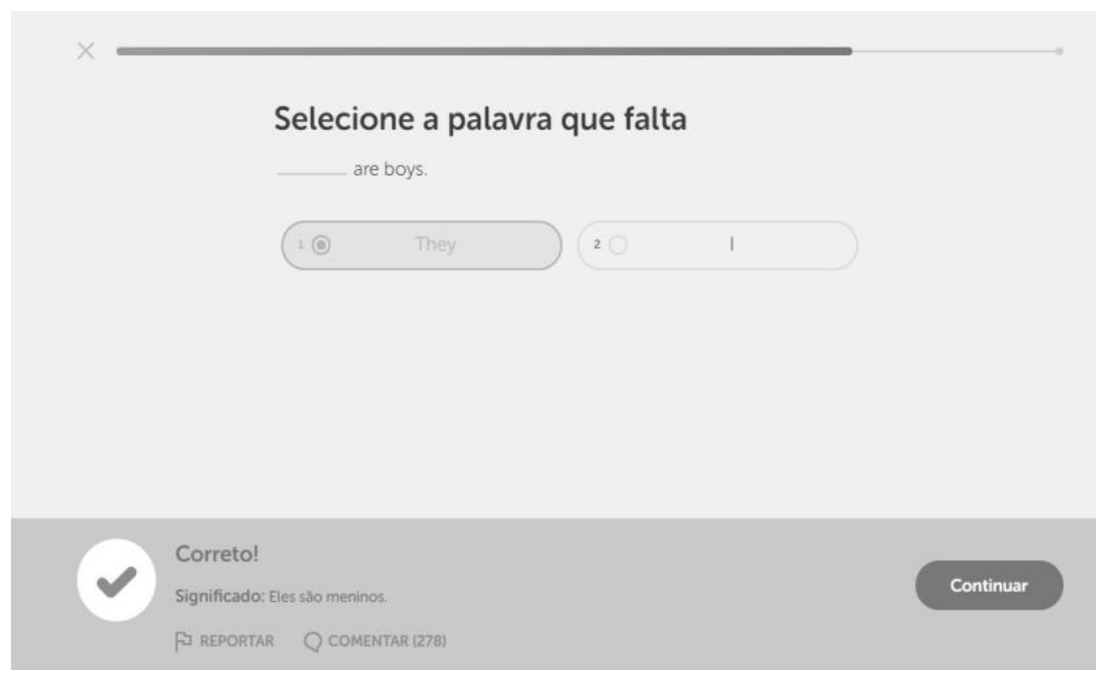

Figura 1: Atividade de gramática no Duolingo

Fonte: https://www.duolingo.com/skill/en/Basics-1

Quanto à reflexão sobre o primeiro encontro, chamamos atenção para a interação que os alunos possuem com a tecnologia: não tiveram dificuldades na instalação do aplicativo Duolingo nos seu smartphones. Quando foi comunicado que a explicação dos assuntos do encontro seria no quadro, houve algumas reclamações iniciais, no entanto, foram contornadas no momento em que foi dito que ainda na aula seria utilizado o aplicativo. De forma calma, explicou-se o uso dos personal pronouns. Na primeira lição, alunos cometeram erros estruturais, mas o professor foi intervindo à medida em que surgiam as dúvidas. Os alunos ficaram todos concentrados tentando resolver suas atividades. 
Nosso segundo encontro teve a duração de 1h/a. Os objetivos do segundo encontro foram os seguintes: proporcionar aos alunos criarem um novo ambiente de aprendizagem através da tecnologia móvel; estudar o assunto gramatical definite and indefinite articles acompanhado de alguns verbos e vocabulários. Em relação aos procedimentos das aulas, predominou-se o uso do aplicativo Duolingo em sala de aula. Foi solicitado aos alunos que fossem até a introdução do módulo onde se encontrava uma breve explicação do assunto da lição:definite and idefinite articles. Eles visualizaram frases, questões já respondidas e suas estruturas gramaticais e vocabulários tanto dessa lição quanto da atividade passada, atualizando a potencialidade do aplicativo descrita a seguir:

[...] em cada fase ou atividade, são trabalhadas palavras específicas, selecionadas previamente. $\mathrm{O}$ jogo apresenta o que será trabalhado em cada etapa. As estruturas também se encontram, de certa forma, situadas no nível linguístico em que o jogador se encontra. O Duolingo oferece a tradução das palavras sempre que o aluno clica em cima delas, antes de realizarem a atividade. Em algumas delas, como verbos, há não só a tradução como também a conjugação e alguma explicação gramatical, por exemplo. (DUARTE; ALDA; LEFFA, 2016, p. 124).

Em seguida, foi comunicado a eles que poderiam ir para qualquer local do campus que tivesse sinal de internet, estudassem a lição e respondessem às questões em seus smartphones. Quanto à reflexão sobre esse encontro, ressaltamos que as aulas foram trabalhadas somente no aplicativo, e os alunos ficaram acompanhando com bastante atenção a explicação do conteúdo pelo próprio aplicativo. O professor estava acompanhando suas ações pela sala virtual do Duolingo for School. Essa funcionalidade possibilita ao professor realizar o acompanhamento do progresso dos alunos em suas lições no aplicativo. Foi registrado que todos estavam fazendo suas questões dentro do seu tempo.

Nosso terceiro encontro teve a duração de $2 \mathrm{~h} / \mathrm{a}$. O objetivo do terceiro encontro foi único:revisar os conteúdos através da sala virtual do Duolingo for School. Em relação aos procedimentos, essa aula foi ministrada diretamente da sala virtual e mostrada no Datashow para que os alunos fossem identificando os seus erros e tirassem suas dúvidas.Quanto à reflexão sobre esse encontro, percebemos que a revisão foi de grande valia, pois fiz com que os alunos pudessem repensar suas respostas às atividades dos encontros iniciais sem muito acúmulo do que já havia sido ministrado. A maioria dos alunos compreendeu a discussão do 
problema proposto e tomou consciência dos erros.

Nosso quarto encontro teve a duração de 1h/a. O objetivo do quarto encontro foi único: trabalhar a aula em grupo pelo aplicativo Duolingo, funcionalidade da versão for School. Em relação aos procedimentos, no momento em que todos os alunos estavam reunidos em sala de aula, foi comunicado a eles que já se havia novas questões liberadas no aplicativo, e que essas envolviam tanto gramática quanto vocabulário de assuntos estruturais estudados previamente. As atividades propostas pressupunham o uso do tempo para além da sala de aula. Foi comunicado aos alunos que eles poderiam se reunir em grupos e que poderiam ir para qualquer local do campus que tivesse acesso à internet. Quanto à reflexão sobre esse encontro, observamos que trabalhar em grupos com o aplicativo causou uma certa estranheza nos alunos, mas, ao mesmo tempo, proporcionou um novo método na utilização do aplicativo. Os alunos não estavam acostumados com esse tipo de atividade, o que exigiu um maior tempo de explicação sobre as potencialidades da tecnologia por parte do professor.

Nosso quinto encontro teve a duração de $2 \mathrm{~h} / \mathrm{a}$. Os objetivos do quinto encontro foram os seguintes:iniciar os conteúdos gramaticais Possessive adjectives e Possessive Pronoun; trabalhar o conteúdo The weather; apresentar alguns verbos e o plural de substantivos. Em relação aos procedimentos, nesse dia começamos trabalhar no quadro branco explicando as diferenças de aplicação do Possessive adjectives e do Possessive Pronoun nas frases. Foi solicitado aos alunos que ligassem seus smartphones, entrassem no Duolingo e formassem grupos à vontade e depois respondessem às questões desbloqueadas. Antes do término da aula, foi comunicado que, no período da tarde, já estariam liberadas mais questões por quatro dias no aplicativo. A seguir, na Fig. 2, podemos observar uma das atividades de gramática e vocabulário do Duolingo solicitando a tradução de português para o inglês envolvendo o conteúdo ministrado. 


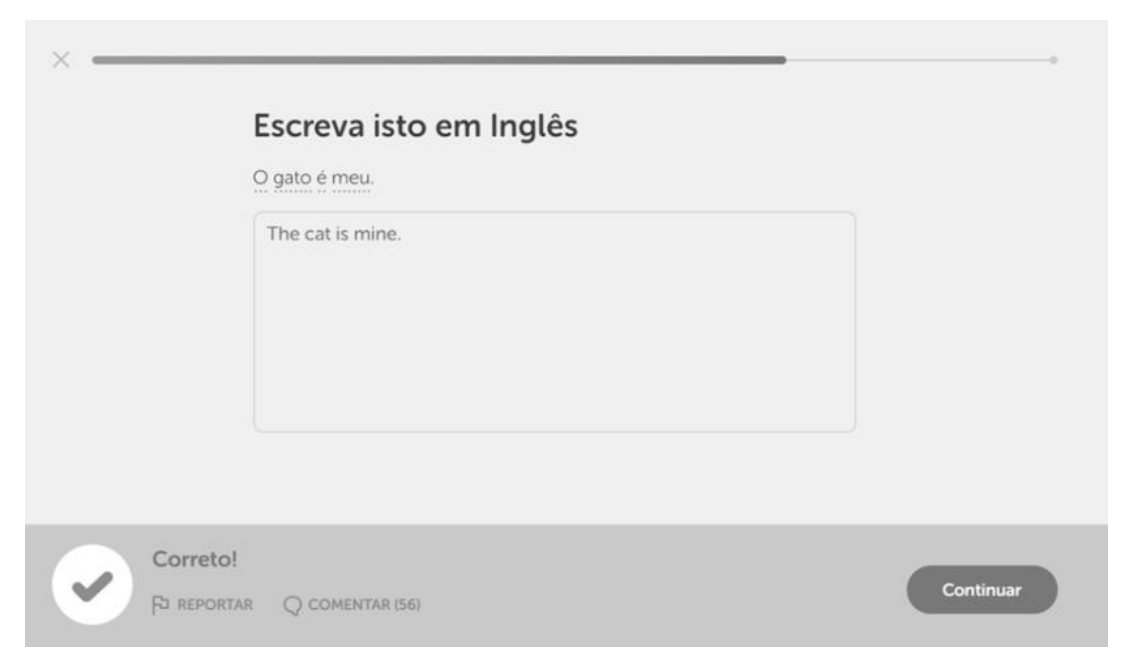

Figura 2.Atividade de gramática e vocabulário do Duolingo

Fonte: https://www.duolingo.com/skill/en/Basics-1-1

Quanto à reflexão sobre o quinto encontro, pudemos perceber que os alunos passaram a aguardar um momento de explicação sobre os conteúdos por parte do professor, através do quadro branco, momento anterior ao de realização de atividades no aplicativo Duolingo. Com isso, todos ficaram atentos à explicação dos assuntos no quadro branco. A reação à quantidade de atividades a ser resolvida como tarefa de casa foi tranquila, o que geralmente não acontece.

Nosso sexto encontro teve a duração de $2 \mathrm{~h} / \mathrm{a}$. Os objetivos do sexto encontro foram os seguintes: iniciar o assunto gramatical Object Pronouns; promover atividades que ajudem os alunos a identificar com mais facilidades os usos dos pronomes estudados. Em relação aos procedimentos, nesse penúltimo encontroa aula foi iniciada através da escrita dos Object Pronouns (me, you, him, her it, us, you, them) no quadro branco, juntamente com exemplos de mostrar seus usos: I love Bob; I love him; He loves her; entre outros. Nos exemplos apresentados, foi usado vocabulário estudado previamente. Em seguida, foram liberadas questões usando o assunto estudado para serem respondidas no aplicativo Duolingo. Quanto à reflexão sobre esse encontro, flagramos que os alunos tiveram mais dificuldades com a compreensão do assunto. Essa dificuldade ficou evidente tanto durante a explicação do conteúdo no quadro branco quanto na resolução das atividades no aplicativo.

Nosso sétimo e último encontro teve a duração de $2 \mathrm{~h} / \mathrm{a}$. O objetivo do último encontro foi único: realizar um Teste de Diagnóstico Final (TDF). Em relação aos 
procedimentos, nesse último encontro foi aplicado o TDF, composto por 35 questões no total, das quais: 18 são de múltipla escolha, envolvendo questões de estrutura gramatical; 07 questões são de associação envolvendo vocabulário; e 10 questões são de tradução de frases. Quanto à reflexão sobre o último encontro e o TDF, registramos a frequência dos 31 alunos. Registramos também que os alunos apresentaram uma maior dificuldade nas questões envolvendo questões de estrutura gramatical: 5 alunos tiveram um rendimento abaixo de 60\%. Nas questões de associação envolvendo vocabulário e de tradução de frases, 30 alunos obtiveram um rendimento acima de $60 \%$.

De maneira geral, através da observação, percebeu-se o comprometimento dos alunos na realização das atividades, sejam em grupos ou individuais, através do aplicativo Duolingo instalado nos seus smartphones. Poucas vezes o professor era chamado para orientar em alguma dúvida que surgisse. No entanto, para desenvolver ações referentes ao ensino de gramática e vocabulário fazendo uso do Duolingo, é preciso criar o ambiente de interação em sala de aula com essas tecnologias previamente. O professor de inglês precisa praticar as lições ofertadas pelo aplicativo para fazer sua avaliação e identificar o que pode ser aproveitado na sala de aula ou como atividade extraclasse. Além disso, é importante haver um momento de explicação sobre as potencialidades e as limitações do aplicativo para que os alunos tenham consciência de que as atividades ofertadas podem promover a internalização de estruturas e o aumento do vocabulário em língua inglesa, mas carecem da interação social, que nos é muito cara no contexto de ensino-aprendizagem de línguas em geral.

\section{Considerações finais}

No planejamento do ensino com o uso do aplicativo Duolingo em aulas de língua inglesa, pensamos que poderíamos ter dificuldades na intervenção pedagógica devido aos alunos não serem de um curso com formação que envolvesse a informática e também por não promover nenhum tipo de conceito ou notas para os alunos no decorrer do ano letivo. Ao contrário do que pensamos, à respeito da aceitação dos alunos, obtivemos reações positivas, pois o que se viu em sala de aula é que a intervenção que faz uso de tecnologias 
digitais é bem-vinda no contexto descrito.

É importante ressaltar que, mesmo com os avanços tecnológicos, não se pode deixar de lado o trabalho que o professor pode fazer com o uso do quadro branco e do pincel. Em experiências de ensino de línguas que pressupõem o uso de tecnologias digitais, o momento presencial de interação entre professor e alunos é fundamental para resolução de dúvidas de natureza comunicativa ou de procedimentos.

Através dom-learning, percebemos que podemos promover o ensino-aprendizagem de língua inglesa, possibilitando aulas mais atraentes para os alunos, podendo amenizar a evasão em sala de aula, levando em consideração o registro da presença massiva da participação dos 31 alunos na intervenção pedagógica relatada. No que tange ao Duolingo como uma ferramenta de suporte ao ensino de gramática e vocabulário de inglês, vimos que ele é motivacional e pode ser utilizado dentro e fora da sala de aula. A ferramenta tecnológica passou a impressão de um aplicativo dinâmico, interativo, útil em um ambiente escolar que tenha conexão com a internet, oferecendo também a possibilidade de contato com a língua estrangeira para além da sala de aula.

Uma potencialidade a ser destacada é a possibilidade de o aplicativo criar grupos (sala de aula virtual) que proporciona um melhor acompanhamento dos alunos diante do que estão produzindo, suas evoluções e pontos a serem melhorados. Uma fragilidade percebida no aplicativo é a pequena quantidade de questões envolvendo oralidade, como também a falta de textos para leitura. O ensino de gramática e vocabulário de inglês, portanto, restringe-se a contextos muito limitados de frases isoladas. De qualquer forma, nossa experiência com o uso do Duolingo foi possível, sobretudo porque os conteúdos prescritos no Projeto Pedagógico de Curso (PPC) listam estruturas gramaticais e vocabulário em língua inglesa.

Por fim, procuramos fazer uso da tecnologia para ensino a língua inglesa como língua estrangeira, mas destacamos que ela, somente, não pode nos conduzir a um processo de ensino-aprendizagem mais efetivo. O processo de ensino-aprendizagem necessita de planejamento que considere os interesses dos alunos e os objetivos específicos de cada disciplina. 


\section{Referências}

DAMIANI, M. F. Sobre pesquisas do tipo intervenção - painel: as pesquisas do tipo intervenção e sua importância para a produção de teoria educacional. IN: XVI ENCONTRO NACIONAL DE DIDÁTICA E PRÁTICA DE ENSINO, 2012, CAMPINAS. Anais do XVI Encontro Nacional de Didática e Prática de Ensino.Campinas: UNICAMP, 2012. p. 2882-2890.

DUARTE, G. B.; ALDA, L.; LEFFA, V. Gameficação e o feedback corretivo: considerações sobre a aprendizagem de línguas estrangeiras pelo Duolingo. Raído, Dourados, MS, v. 10, n. 23, jul./dez, 2016.

GEDDES, S. J. Mobile learning in the 21st century: benefit to learners. Knowledge Tree ejournal, v. 30, n. 3, p. 214-228, 2004.

GUERRA, W. T. Ensino de inglês para fins específicos e multiletramentos na oferta técnica da escola pública. 2017. Dissertação (Mestrado em Ensino) - Programa de Pós-Graduação em Ensino (UERN, UFERSA, IFRN), Instituto Federal do Rio Grande do Norte, Mossoró, 2017.

KENSKI, V. M. Educação e Tecnologias:o novo ritmo da informação.Campinas: Papirus, 2007.

MOURA, A. M. C. Apropriação do telemóvel como ferramenta de mediação em mobile learning: estudo de caso em contexto educativo. 2010. Tese (Doutorado em Ciências da Educação) - Universidade do Minho, Braga, 2010.

PINTO, M. M. D. S.; LIMA, S. C. A língua portuguesa na Educação Profissional e Tecnológica: uma proposta de ensino do gênero textual relatório de aula prática no PROEJA. Revista de Estudos e Pesquisas sobre Ensino Tecnológico, v. 4, p. 195-207, 2018.

REIS, A. R.; LIMA, S. C. Uma proposta de ensino complementar para os multiletramentos na Educação Profissional. Interseç̧ões. Revista de Estudos sobre Práticas Discursivas e Textuais, v. 11, p. 249-263, 2018.

SACCOL, A.; SCHLEMMER, E.; BARBOSA, J. M-learning e u-learning: novas perspectivas da aprendizagem móvel e ubíqua. São Paulo: Pearson Prentice Hall, 2011.

SHARMA, S. K. et al. Web services model for mobile, distance and distributed learning using service-oriented architecture. International Journal of Mobile Communications, 4 (2), p. 178192, 2006.

SILVA, G. M. O ensino de inglês em turmas numerosas: uma proposta de ensino da pronúncia em cursos técnicos de nível médio do Instituto Federal do Rio Grande do Norte. 2018. Dissertação (Mestrado em Ensino) - Programa de Pós-Graduação em Ensino (UERN, UFERSA, IFRN), Instituto Federal do Rio Grande do Norte, Mossoró, 2018. 
SOARES, K. R. B. M-learning: o uso do aplicativo Duolingo para o ensino de gramática e vocabulário em língua inglesa em curso técnico de nível médio. 2018. Dissertação (Mestrado em Ensino) - Programa de Pós-Graduação em Ensino (UERN, UFERSA, IFRN), Instituto Federal do Rio Grande do Norte, Mossoró, 2018.

Data de submissão: 21/04/2019. Data de aprovação: 19/05/2019. 